\title{
BMI-1 and survivin expression with clinicopathological correlation and prognostic impact in $B$ and T/NK- cell non-Hodgkin lymphoma
}

\author{
Nahed A. Soliman*1,2, Lamia Abdalkader ${ }^{2}$, Doaa Shams Eldin Ghorab ${ }^{2}$ \\ ${ }^{1}$ Department of Pathology, Faculty of Medicine, Helwan University, Helwan, Egypt \\ ${ }^{2}$ Department of Pathology, Oncology Center, Faculty of Medicine, University of Mansoura, Mansoura, Egypt
}

Received: May 12, 2019

DOI: $10.5430 /$ jst.v9n2p11
Accepted: June 3, 2019

Online Published: June 10, 2019

\begin{abstract}
Background: The pathogenesis of non-Hodgkin lymphoma is a complex process that involves several molecular changes. Alterations in polycomb group proteins as well as Survivin have been described but details are still lacking particularly in T/NK-cell lymphomas. Polycomb proteins have a big role in cell cycle and differentiation. Survivin is another recently recognized player in non-Hodgkin lymphoma.

Objective: To study the pattern of Bmi-1 and Survivin in different categories of B- and T/NK- cell non-Hodgkin lymphomas, their association with the clinicopathological parameters, and their impact on the prognosis of non-Hodgkin lymphomas.

Material\& methods: Immunohistochemical staining was used to study paraffin samples of 267 patients' biopsies. We used tonsils and reactive lymph node as normal control.

Results: Both Bmi-1 and Survivin showed significant upregulation in several subtypes B- $(P=.000-.02$ for Bmi- 1 and $.00-.03$ for Survivin) and T/NK cell lymphomas ( $P=.009-.03$ for Bmi-1 and 0.008- 0.009 for Survivin) compared to normal tissue. Significant positive correlation between Bmi-1 and Survivin was detected in both $\mathrm{B}-\left(\mathrm{Co}=0.539^{* *}, P=.00\right)$ and $\mathrm{T}$ - cell lymphomas $(\mathrm{Co}=$ $0.560^{* *}, P=.000$ ). A statistically significant difference between overall survival and expression of both BMI- 1 and Survivin was detected $(P=.00$ for BMI-1and survivin).

Conclusion: Bmi-1 and Survivin show significant upregulation as well correlation with clinicopathological parameters and overall survival of non-Hodgkin lymphomas.
\end{abstract}

Key Words: Polycomb group protein, BMI-1, Survivin, Non-Hodgkin lymphomas, Prognosis

\section{INTRODUCTION}

Non-Hodgkin's lymphomas (NHLs) include diverse morphological and prognostic groups of cancer that originate from lymphoid cells. Recently gene analysis allows us to better recognize the biology and molecular classification of such tumors. The study of the gene pattern discovered new oncogenic pathways of carcinogenesis. ${ }^{[1,2]}$ Like most of cancer, NHLs arise by cumulative effect of genetic abnormalities that result in formation of monoclonal malignant cell. The initial genetic abnormality is recurrent translocations which led to upregulation of oncogenes responsible for control of cell proliferation, survival, and differentiation. ${ }^{[2]}$ Nogai et al. described epigenetic changes that occur as well during the process of lymphomagenesis. ${ }^{[1]}$ DNA methylation, histone modifications, chromatin remodeling and change in gene expression caused by non-coding RNAs (ncRNAs) are

\footnotetext{
* Correspondence: Nahed A. Soliman; Email: nahedram@yahoo.com; Address: Department of Pathology, Faculty of Medicine, Helwan University, Helwan, Egypt.
} 
the major epigenetic changes. ${ }^{[3,4]}$ Chromatin modification occurs either by histone tail acetylation resulting in gene activation and methylation, which result in silencing. ${ }^{[5]}$ PCG proteins are large multisubunits known as Polycomb repressive complexes (PRCs), which can modify histone by binding to chromatin. In mammals, there are two main PCG complexes: (PRC1) and (PRC2). ${ }^{[6]}$ PRC1 complexes differ in their role and localization. PRC1 has Six subgroups PRC1.1 to PRC.1.6. ${ }^{[7-9]}$ PCG complexes control the development of stem cell and cancer cell through regulation of the cell cycle, differentiation and proliferation. ${ }^{[10]}$ A little is known about the pattern of PCG proteins and their role in the development of lymphoma, especially T/NK-cell lymphomas. ${ }^{[11]}$ B-cell-specific Mo-MLV insertion site-1 (BMI1) is a member of the polycomb group (PCG) proteins that grant stem cell characteristics through gene silencing. ${ }^{[12]}$ Bmi-1/PCGF4 is responsible for induction of lymphomas in mice. ${ }^{[13]}$ In reactive lymphoid tissues, BMI1 expression is strongly evident in mantle zone B lymphocyte and moderate in interfollecular/ intrafollecular CD3+ T and CD56+ NK/T cells. Abd Al Kader et al. reported that both aggressive B cell lymphomas and indolent lymphoma can strongly express BMI ${ }^{[10]}$ However other studies concluded that Bmi-1 is associated with a bad prognosis. ${ }^{[10,14-17]}$ Survivin, is one of the inhibitor of apoptosis (IAP) family, is virtually undetected in terminally differentiated tissues but overexpressed in many malignancies such as B-cell lymphomas (high-grade). ${ }^{[18]} \mathrm{It}$ was reported that survivin can promote carcinogenesis by inhibition of cell apoptosis, stimulating cell proliferation, regulating cell mitosis and possibly angiogenesis. ${ }^{[18-20]}$ BMI-1 and Survivin have a big role in cancer chemoresistance. ${ }^{[21]}$ This motivated Zhang et al. 2016 to identify a novel protein targeted against survivin and Bmi-1 (miR-203). This targeted therapy aimed to inhibits proliferation and self-renewal of leukemia stem cells. ${ }^{[21]}$ The current study investigates the pattern of expression of Bmi-1 and survivin in different variants of B- as well as T cell lymphomas and corresponding cell of origin using unique antisera against both with clinicopathological correlation. The survival of the patients is also evaluated.

\section{MAterials AND Methods}

\subsection{Patient samples \& construction of microarray}

Paraffin blocks of 267 lymphoma and 5 reactive lymphoid hyperplasia (RLH) samples from the archives of, Oncology Center, Faculty of Medicine, Mansoura University, Egypt were used for the present analyses between October 2008 and November 2012. The clinical data of the patients, the site, the stage, and the prognosis of the neoplasms (death, clinical relapse either after complete or partial remission) are summarized in Table 1. The duration of follow up was from 0-52 months with a median of 20 months for BCL and 24 months for TCL. Written consent was signed by all patients for the use of their tissue samples in research. The ethics committee of Mansoura University approved The research idea. REAL/WHO classification was used to classify the study cases. Hans algorithm was used to classify DLBCL into germinal center type (DLBCL-GCB) and non-germinal center type (DLBCL non-GCB) ${ }^{[22,23]}$ Manual tissue microarray (TMA) was prepared by pencil tip. ${ }^{[24-27]}$ Three 1-mm cores/ case were prepared. Reactive lymphoid hyperplasia (5 specimens) was used as normal controls. Examination of H\&E-stained sections of the final microarray blocks was done.

\subsection{Immunohistochemical staining}

Immunodetection was performed using Ventana Benchmark Ultra machine automated staining system. The following rabbit monoclonal antibodies were used: Bmi-1 (Bmi1(D20B7) $\mathrm{XP}^{\circledR}$ Rabbit mAb \#6964), Survivin (Survivin (71G4B7) Rabbit $\mathrm{mAb}$ \#2808). The slides were investigated by 3 pathologists. We put the intensity of staining as well as the percentage of positive tumor cells into consideration in each high-power field. ${ }^{[10]}$ The internal control for Bmi-1 was endothelial cells and adjacent normal lymphocytes. An external control tissue was put in each staining run. The immunophenotyping of each case was detected by a panel of markers (including CD20, CD138, CD10, CD3, CD4, Cyclin-D1 and BCL2). Negative controls were done via replacing primary antibody with PBS.

\subsection{Statistical analysis}

SPSS version 20 software program was used for statistical analysis. All variables were non parametric except for age of the cases was parametric identified by Kolmogorov-Smirnov Z. test. Mann-Whitney and Kruskal-Wallis tests were used to evaluate Categorical data. While One way ANOVA test evaluated continuous data (age). The tests were considered statistically significant when the $P$ value less than .05 . Overall survival (from date of diagnosis to death) and disease-free survival (clinical relapse after partial or complete remission) were determined by Kaplan-Meier test. The log-rank test was used to compare groups. Spearman's coefficients tests were used for the correlation analyses of Bmi-1 and Survivin in either BCL and TCL.

\section{RESULTS}

This study was done retrospectively on 267 cases of lymphoma and 5 RLH specimens. The mean age of the patients was $58.1 \pm 13.6$ in BCL and $48.3 \pm 19.5$ in TCL. The clinicopathological characteristics of the studied cases of NHL 
(age, location, stage, follow-up period, overall survival and disease free survival) were illustrated in Table 1. The expression of BMI-1 and Survivin in both types of NHL and normal lymphoid tissue were demonstrated in Table 3 . The significant difference of expression of BMI- 1 and survivin between lymphoid neoplasms and their cell of origin were presented in Table 4. The difference in expression of both markers between subtypes of either BCL and TCL were shown in Table 5. The correlations of expression of both markers and clinicopathological parameters of NHL were illustrated in Table 2. Significant positive correlation between both markers in BCL and TCL was displayed in Figure 1. Lastly, the relationship of expression of both markers and survival of the cases were shown in Figure 2.

Table 1. Clinicopathological characteristics of the studied cases

\begin{tabular}{|c|c|c|c|c|c|c|c|c|c|c|c|c|c|c|c|}
\hline & \multirow[t]{2}{*}{ Age } & \multicolumn{2}{|c|}{ Sex } & \multicolumn{2}{|c|}{ Location } & \multicolumn{4}{|c|}{ Stage } & \multirow{2}{*}{$\mathbf{T}$} & \multicolumn{2}{|l|}{$\mathrm{OS}^{\mathrm{a}}$} & \multicolumn{2}{|c|}{ EFS $^{\mathbf{a}}$} & \multirow{2}{*}{$\mathbf{T}$} \\
\hline & & $\mathbf{M}$ & $\mathbf{F}$ & $\mathbf{N}$. & E.N. & I & II & III & IV & & yes & no & yes & no & \\
\hline $\mathrm{BL}$ & $52.7 \pm 18.7$ & 8 & 2 & 2 & 8 & 0 & 3 & 7 & 0 & $4-40$ (29) & 3 & 7 & 7 & 3 & 10 \\
\hline DLBCL-GCB & $53.2 \pm 16.9$ & 11 & 18 & 25 & 4 & 3 & 6 & 14 & 6 & $1-45(35)$ & 16 & 9 & 15 & 10 & 29 \\
\hline DLBCL -NGCB & $57.2 \pm 12.4$ & 51 & 42 & 66 & 27 & 9 & 7 & 49 & 28 & $1-42(15)$ & 33 & 34 & 10 & 57 & 93 \\
\hline FLG3 & $57.6 \pm 14.9$ & 10 & 8 & 16 & 2 & 0 & 0 & 11 & 7 & $0-52$ (15) & 7 & 9 & 3 & 13 & 18 \\
\hline MCL & $63.4 \pm 8.8$ & 11 & 4 & 10 & 5 & 0 & 0 & 15 & 0 & $1-50(24)$ & 11 & 3 & 0 & 14 & 15 \\
\hline FLG1-2 & $61.3 \pm 8.7$ & 16 & 7 & 13 & 10 & 3 & 7 & 11 & 2 & $1-50(36)$ & 14 & 6 & 4 & 16 & 23 \\
\hline PCM & $69 \pm 9$ & 7 & 3 & 0 & 10 & 3 & 0 & 2 & 5 & 6-36 (11) & 2 & 8 & 0 & 10 & 10 \\
\hline PC & $65.6 \pm 15.7$ & 5 & 1 & 1 & 5 & 0 & 0 & 2 & 4 & $5-40(10)$ & 2 & 4 & 0 & 6 & 6 \\
\hline CLL/SLL & $54.3 \pm 13.8$ & 10 & 4 & 14 & 0 & 2 & 0 & 5 & 7 & 6-51 (32) & 6 & 7 & 3 & 10 & 14 \\
\hline MALT lymphoma & $61.9 \pm 15.4$ & 3 & 7 & 0 & 10 & 0 & 6 & 4 & 0 & 6-36 (12) & 7 & 3 & 4 & 6 & 10 \\
\hline B-cell neoplasms & $58.1 \pm 13.6$ & 132 & 96 & 147 & 81 & 20 & 29 & 120 & 59 & $0-52(20)$ & 122 & 89 & 49 & 162 & $\begin{array}{l}22 \\
8\end{array}$ \\
\hline T-LBL & $34.5 \pm 19.9$ & 10 & 4 & 11 & 3 & 0 & 0 & 0 & 14 & 1-39 (19) & 6 & 7 & 3 & 10 & 14 \\
\hline PTCL & $58.9 \pm 15.3$ & 3 & 8 & 5 & 6 & 0 & 0 & 4 & 7 & $1-48(24)$ & 7 & 4 & 2 & 9 & 11 \\
\hline ALCL & $53.9 \pm 14.1$ & 8 & 6 & 11 & 3 & 2 & 0 & 8 & 4 & $0-52(24)$ & 4 & 8 & 2 & 10 & 14 \\
\hline Tcell lymphoma & $48.3 \pm 19.5$ & 21 & 18 & 27 & 12 & 2 & 0 & 12 & 25 & $0-52(24)$ & 17 & 19 & 7 & 29 & 39 \\
\hline
\end{tabular}

Note. BL: Burkitt lymphoma, DLBCL-GCB: Diffuse large cell B cell lymphoma germinal center type, DLBCL non-GCB: Diffuse large B- cell lymphoma non germinal center type, FLG3:Follicular lymphoma grade3, FLG1: Follicular lymphoma grade 1,2, MCL: Mantle cell lymphoma, CLL/SLL: Chronic lymphocytic leukemia/small lymphocytic lymphoma, PCM: Plasma cell myeloma, PC: Plasmacytoma, MALT: Mucosa associated lymphoid tissue, T-LBL: T-cell lymphoblastic lymphoma, PTCL: Peripheral T-cell lymphoma, ALCL: Anaplastic large cell lymphoma. M: Male; F: Female; N: Nodal; E.N.: Extra Nodal; T: Time of follow up; OS: Overall Survival; EFS: Event Free Survival. a: some cases were excluded due to loss of follow-up or died unrelated to lymphoma.

3.1 Clinicopathological characteristics of the study cases\& its correlation with BMI-1 and Survivin expression(see Tables 1, 2)

B cell neoplasm cases were 228 . The mean age of them was $58.1 \pm 13.6$. 132 of them were male, 147 cases were nodal, most of them were in stage $3(n=120) .122$ cases were alive till the last date of contact during the period of the follow up. 162 of the cases showed clinical relapse after partial or complete remission. The most prevalent subtype of lymphoma in our study was DLBCL-NGC, which was characterized by male predominance, nodal location, higher stage (III, IV), lower OS and higher rate of relapse. T cell neoplasm cases

Published by Sciedu Press

were 39. The mean age of them was $48.3 \pm 19.5 .21$ of them were male, 27 cases were nodal, most of them were in stage $4(n=25) .19$ cases were died during the period of the follow up. 29 of the cases showed clinical relapse after partial or complete remission. In this study, the expression pattern of BMI-1 was significantly associated with the stage, overall survival, and event free survival of NHL patients (KruskalWallis Test $p=.00, .00, .001$ respectively). Also significant association between the pattern of expression of survivin and the stage, overall survival, and event free survival of NHL patients were also noticed (Kruskal-Wallis Test $p=.00, .00$, 0.03 respectively) (see Table 2 ). 
Table 2. Correlations of expression of BMI-1 and Survivin and clinicopathological parameters of NHL

\begin{tabular}{|c|c|c|c|c|c|c|c|c|c|c|c|c|c|c|}
\hline \multirow{2}{*}{ BMI-1 } & \multirow{2}{*}{ Age } & \multicolumn{2}{|l|}{ Sex } & \multicolumn{2}{|c|}{ Location } & \multicolumn{4}{|l|}{ Stage } & \multicolumn{2}{|l|}{$\mathrm{OS}^{\mathbf{a}}$} & \multicolumn{2}{|c|}{ EFS $^{\mathbf{a}}$} & \multirow{2}{*}{$\mathbf{T}$} \\
\hline & & $\mathbf{M}$ & $\mathbf{F}$ & $\mathbf{N}$ & EN & I & II & III & IV & yes & no & yes & no & \\
\hline negative & $54 \pm 13$ & 3 & 2 & 3 & 2 & 2 & 1 & 2 & 0 & 5 & 0 & 3 & 2 & 5 \\
\hline+ & $49 \pm 19$ & 10 & 8 & 10 & 8 & 7 & 4 & 5 & 2 & 13 & 3 & 5 & 11 & 18 \\
\hline++ & $57 \pm 14$ & 95 & 83 & 123 & 55 & 11 & 22 & 105 & 40 & 105 & 57 & 44 & 118 & 178 \\
\hline+++ & $57 \pm 16$ & 43 & 21 & 38 & 28 & 2 & 2 & 20 & 42 & 16 & 48 & 4 & 60 & 66 \\
\hline $\mathrm{P}$ & .14 & .36 & & .29 & & $.000 *$ & & & & $.00 *$ & & $.001^{*}$ & & 267 \\
\hline \multicolumn{15}{|l|}{ Survivin } \\
\hline negative & $56 \pm 14$ & 1 & 2 & 2 & 1 & 0 & 1 & 2 & 0 & 2 & 1 & 1 & 1 & 3 \\
\hline+ & $55 \pm 15$ & 9 & 7 & 9 & 7 & 9 & 3 & 2 & 2 & 11 & 5 & 4 & 12 & 16 \\
\hline++ & $56 \pm 14$ & 96 & 84 & 126 & 54 & 11 & 22 & 104 & 43 & 109 & 58 & 45 & 122 & 180 \\
\hline+++ & $59 \pm 17$ & 37 & 31 & 45 & 21 & 2 & 3 & 24 & 39 & 17 & 45 & 6 & 56 & 68 \\
\hline $\mathrm{P}$ & .6 & .17 & & .11 & & $.000 *$ & & & & $.00 *$ & & $.03 *$ & & 267 \\
\hline
\end{tabular}

Note. One Way Anova test results for age, and Kruskal-Wallis Test for other parameters. a: some cases were excluded due to loss of follow-up or died unrelated to lymphoma, $*$ : significant statistical tests ( $p$ value is less than .05)

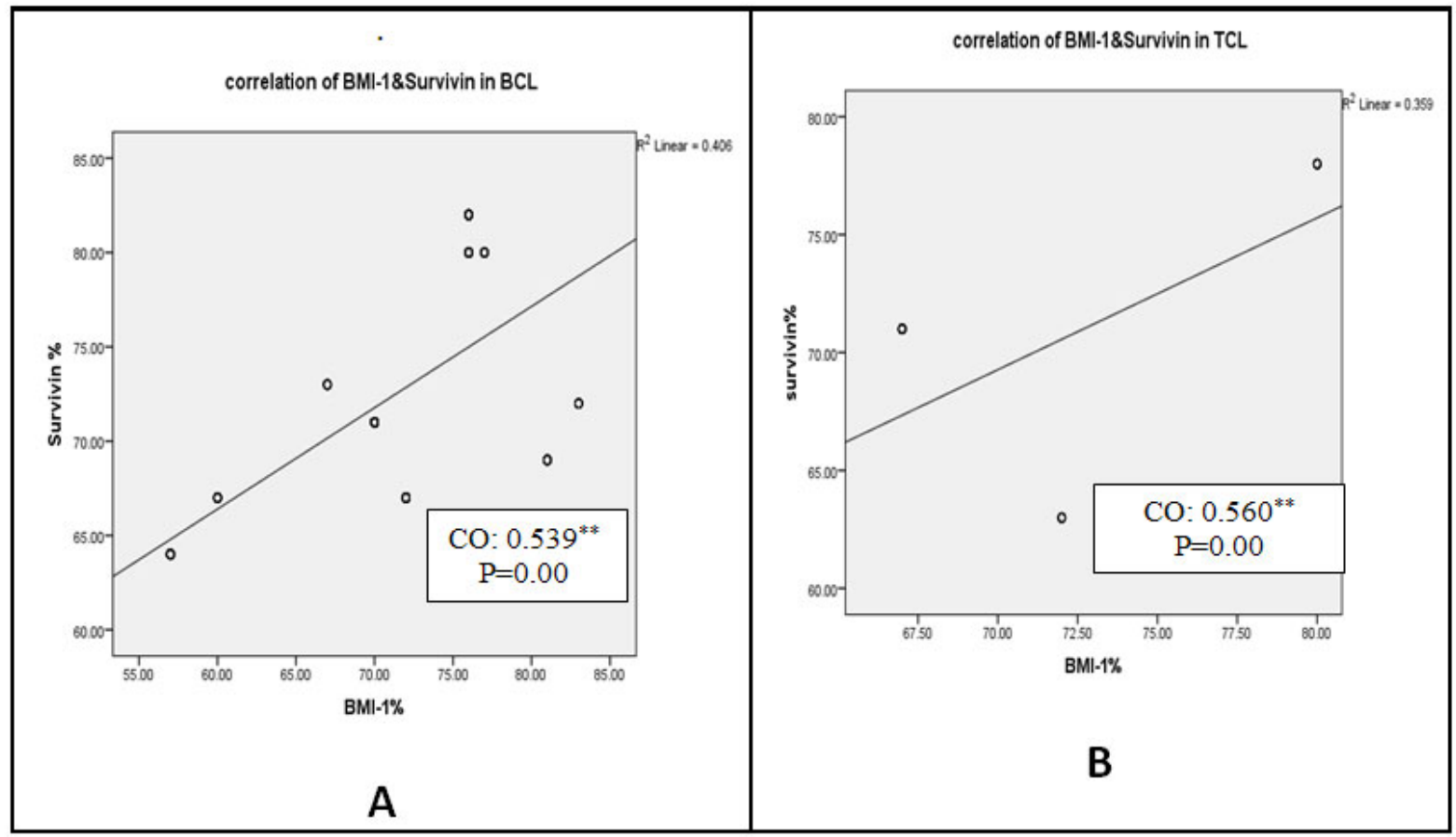

Figure 1. Correlation between BMI-1 with Survivin expression based on percentage of positive cells in both B-and Tcell neoplasms. (A) B-cell neoplasms. (B) T-cell neoplasms. Co, Spearman correlation coefficient (*correlation is significant at the 0.01 level; **correlation is strongly significant).

\subsection{Expression of BMI-1 and survivin in normal lym-} phoid tissues\& NHL (see Tables 3, 4 and 5)

\subsubsection{Expression of BMI-1 and Survivin in normal lym- phoid tissues (see Tables 3 and 5)}

In RLH, mantle zone cells revealed diffuse strong staining of Bmi-1 (73.3\%) and moderate staining of Survivin (40\%). Germinal center cells showed weak expression of Bmi-1
(6.7\%) and strong Survivin signal (46.7\% to 53\%). Post germinal center cells, plasma cells, interfollicular T (CD3+) and follicular T-helper cells (CD4+) showed moderate expression of Bmi-1 (53.3\%) and moderate/weaker staining of Survivin (40\% to 53.3\%) (see Figures 1(A, B), and Table 3). The difference between the BMI-1 expression in germinal and post germinal center cells was statistically significant 
(Kruskal-Wallis Test $p=.003$ ) however, Survivin expression and postgerminal cells (Kruskal-Wallis Test $p=.702$ ) (see was not statistically significant different between germinal Table 5).

Table 3. Bmi1-1 and Survivin expression in different subtypes of B and Tcell neoplasms and normal control

\begin{tabular}{|c|c|c|c|c|c|c|c|c|c|c|c|c|c|}
\hline \multirow[b]{2}{*}{$\begin{array}{l}\text { Malignant lymphoma } \\
\text { normal control }\end{array}$} & \multirow[b]{2}{*}{$\mathbf{N}$} & \multicolumn{6}{|c|}{ Bmi-1 } & \multicolumn{6}{|c|}{ Survivin } \\
\hline & & $\mathbf{0}$ & 1 & 2 & 3 & $\begin{array}{l}\text { Positivity } \\
\text { score } \\
\text { /Max }\end{array}$ & $\begin{array}{l}\text { Positivity } \\
\text { score } \\
\%\end{array}$ & $\mathbf{0}$ & 1 & 2 & 3 & $\begin{array}{l}\text { Positivity } \\
\text { score } \\
\text { /Max }\end{array}$ & $\begin{array}{l}\text { Positivity } \\
\text { score } \\
\%\end{array}$ \\
\hline BL & 10 & 1 & 3 & 3 & 3 & $18 / 30$ & $60 \%$ & 1 & 1 & 5 & 3 & $20 / 30$ & $67.7 \%$ \\
\hline DLBCL- GCB & 29 & 0 & 0 & 21 & 8 & $66 / 87$ & $76 \%$ & 0 & 0 & 16 & 13 & $71 / 87$ & $81.6 \%$ \\
\hline DLBCL non GCB & 93 & 0 & 6 & 71 & 16 & $196 / 279$ & $70.2 \%$ & 0 & 9 & 63 & 21 & $198 / 279$ & $71 \%$ \\
\hline FLG3 & 18 & 0 & 1 & 13 & 4 & $39 / 54$ & $72.2 \%$ & 0 & 0 & 18 & 0 & $36 / 54$ & $66.7 \%$ \\
\hline MCL & 15 & 0 & 1 & 9 & 5 & $34 / 45$ & $75.5 \%$ & 0 & 0 & 9 & 6 & $36 / 45$ & $80 \%$ \\
\hline FLG1 & 23 & 3 & 3 & 15 & 2 & $39 / 69$ & $56.5 \%$ & 1 & 3 & 16 & 3 & $44 / 69$ & $63.7 \%$ \\
\hline PCM & 10 & 0 & 2 & 4 & 4 & $20 / 30$ & $67.7 \%$ & 0 & 1 & 6 & 3 & $22 / 30$ & $73.3 \%$ \\
\hline PC & 6 & 0 & 0 & 3 & 3 & $15 / 18$ & $83.3 \%$ & 0 & 1 & 3 & 2 & $13 / 18$ & $72.2 \%$ \\
\hline CLL/SLL & 14 & 0 & 0 & 8 & 6 & $34 / 42$ & $81 \%$ & 0 & 0 & 13 & 1 & $29 / 42$ & $69 \%$ \\
\hline MALT & 10 & 0 & 0 & 7 & 3 & $23 / 30$ & $76.6 \%$ & 0 & 0 & 6 & 4 & $24 / 30$ & $80 \%$ \\
\hline B-cell neoplasms & 228 & 4 & 16 & 154 & 54 & $486 / 684$ & $71 \%$ & 2 & 15 & 152 & 59 & $496 / 684$ & $72.5 \%$ \\
\hline T-LBL & 14 & 1 & 2 & 4 & 8 & $34 / 42$ & $80.9 \%$ & 0 & 0 & 9 & 5 & $33 / 42$ & $78.6 \%$ \\
\hline PTCL & 11 & 1 & 0 & 6 & 4 & $24 / 33$ & $72.7 \%$ & 0 & 1 & 10 & 0 & $21 / 33$ & $63.6 \%$ \\
\hline ALCL & 14 & 0 & 0 & 12 & 2 & $30 / 42$ & $71.4 \%$ & 1 & 0 & 7 & 6 & $32 / 42$ & $76.2 \%$ \\
\hline Tcell neoplasms & 39 & 2 & 2 & 22 & 14 & $88 / 117$ & $75.2 \%$ & 1 & 1 & 26 & 11 & $86 / 117$ & $73.5 \%$ \\
\hline \multicolumn{14}{|l|}{$\underline{\text { RLH } \text { and tonsil: }}$} \\
\hline Mantle zone & 5 & 0 & 0 & 4 & 1 & $11 / 15$ & $73.3 \%$ & 0 & 4 & 1 & 0 & $6 / 15$ & $40 \%$ \\
\hline GC dark zone & 5 & 4 & 1 & 0 & 0 & $1 / 15$ & $6.7 \%$ & 0 & 2 & 3 & 0 & $8 / 15$ & $53.3 \%$ \\
\hline GC light zone & 5 & 4 & 1 & 0 & 0 & $1 / 15$ & $6.7 \%$ & 1 & 3 & 2 & 0 & $7 / 15$ & $46.7 \%$ \\
\hline Post GC B-cells & 5 & 0 & 0 & 4 & 0 & $8 / 15$ & $53.3 \%$ & 0 & 3 & 2 & 0 & $8 / 15$ & $46.7 \%$ \\
\hline Plasma cells & 5 & 1 & 0 & 4 & 0 & $8 / 15$ & $53.3 \%$ & 3 & 2 & 3 & 0 & $8 / 15$ & $53.3 \%$ \\
\hline $\begin{array}{l}\text { Interfollicular } \\
\text { T-zone }\end{array}$ & 5 & 0 & 2 & 3 & 0 & $8 / 15$ & $53.3 \%$ & 0 & 4 & 1 & 0 & $7 / 15$ & $40 \%$ \\
\hline $\begin{array}{l}\text { Follicular T- helper } \\
\text { cells }\end{array}$ & 5 & 0 & 2 & 3 & 0 & $8 / 15$ & $53.3 \%$ & 0 & 2 & 3 & 0 & $8 / 15$ & $53.3 \%$ \\
\hline NK/T cells & 5 & 0 & 2 & 3 & 0 & $/ 15$ & $53.3 \%$ & 0 & 2 & 3 & 0 & $1 / 15$ & $53.3 \%$ \\
\hline
\end{tabular}

Note. BL: Burkitt lymphoma, DLBCL-GCB: Diffuse large cell B cell lymphoma germinal center type, DLBCL non-GCB: Diffuse large B-cell lymphoma non germinal center type, FLG3: Follicular lymphoma grade3, FLG1: Follicular lymphoma grade 1,2, MCL: Mantle cell lymphoma, CLL/SLL: Chronic lymphocytic leukemia/small lymphocytic lymphoma, PCM: Plasma cell myeloma, PC:

Plasmacytoma, MALT: Mucosa associated lymphoid tissue, T-LBL: T-cell lymphoblastic lymphoma, PTCL: Peripheral T-cell lymphoma, ALCL: Anaplastic large cell lymphoma.

\subsubsection{High expression of BMI-1 and Survivin in B-cell neoplasms (see Tables 3 and 5)}

In B-cell neoplasms, the overall expression of BMI-1 was $71 \%$. The staining intensity was generally moderate/ strong. Bmi-1 expression was found in all subtypes, ranging from $56.5 \%$ in follicular lymphoma grade 1 (FLG1) to $83.3 \%$ in plasmacytoma (PC). All other subtypes showed generally strong expression: $60 \%$ in BL to $67.7 \%$ in plasma cell myeloma (PCM), 70\% in diffuse large B-cell lymphoma nongerminal center (DLBCL non GCB), $72.2 \%$ in Follicular lymphoma grade 3 (FLG3), 75.5\% in Mantle cell lymphoma (MCL), $76 \%$ in diffuse large B-cell lymphoma germinal cen- 3 ).

Published by Sciedu Press ter type (DLBCL-GCB), 76.6\% in mucosa associated lymphoid tissue (MALT) lymphoma, and $81 \%$ in chronic lymphocytic leukemia/small lymphocytic lymphoma (CLL/SLL) (see Figures 2A and Table 3). The overall expression of Survivin in BCL was $73.5 \%$. The staining intensity was generally moderate/strong. Survivin expression was found in all subtypes, ranging from $63.7 \%$ in FLG1 to $81.6 \%$ in DLBCL-GCB. The expression in the other subtypes was: $66.7 \%$ in FLG 3, 67.7\% in BL, 69\% in CLL/SLL, $71 \%$ in DLBCL- non GCB, $72.2 \%$ in PC $73.3 \%$ in PCM, and $80 \%$ in both MCL and MALT lymphoma (see Figure 2B and Table 
The Kruskal-Wallis Test detected a significant difference in the expression of BMI-1and not in survivin expression among the subtypes of B-cell lymphomas $(P=.02$ and .06 respectively) (see Table 5).

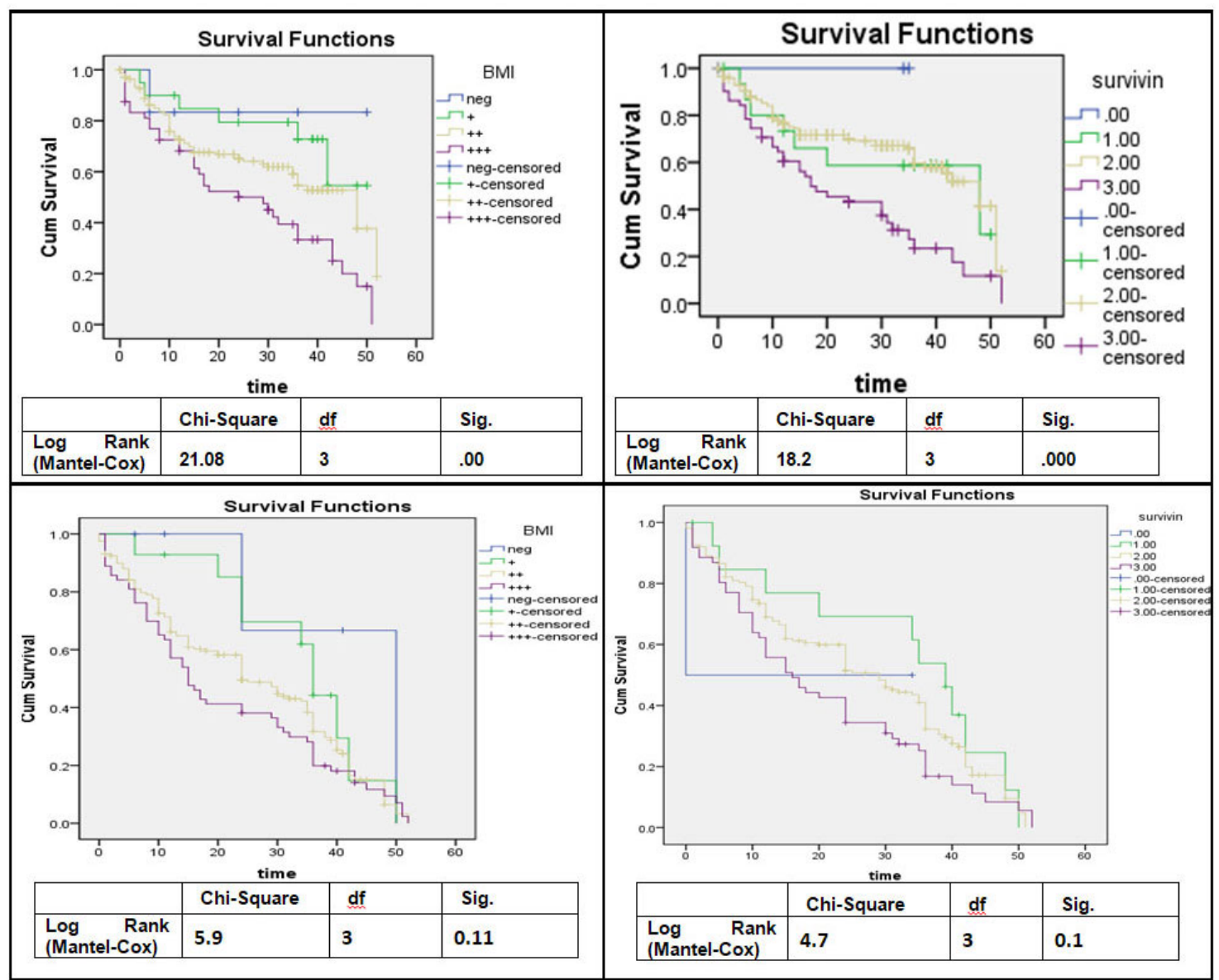

Figure 2. OS and EFD in NHL in relation to expression of BMI-1 and Survivin (A and B) overall survival was significantly related to BMI-1 and Survivin expression in NHL (C and D) Event free survival was not significantly related to BMI-1 and Survivin expression in NHL Kaplan-Meier test (survival tests is significant at the 0.01 level; **correlation is strongly significant).

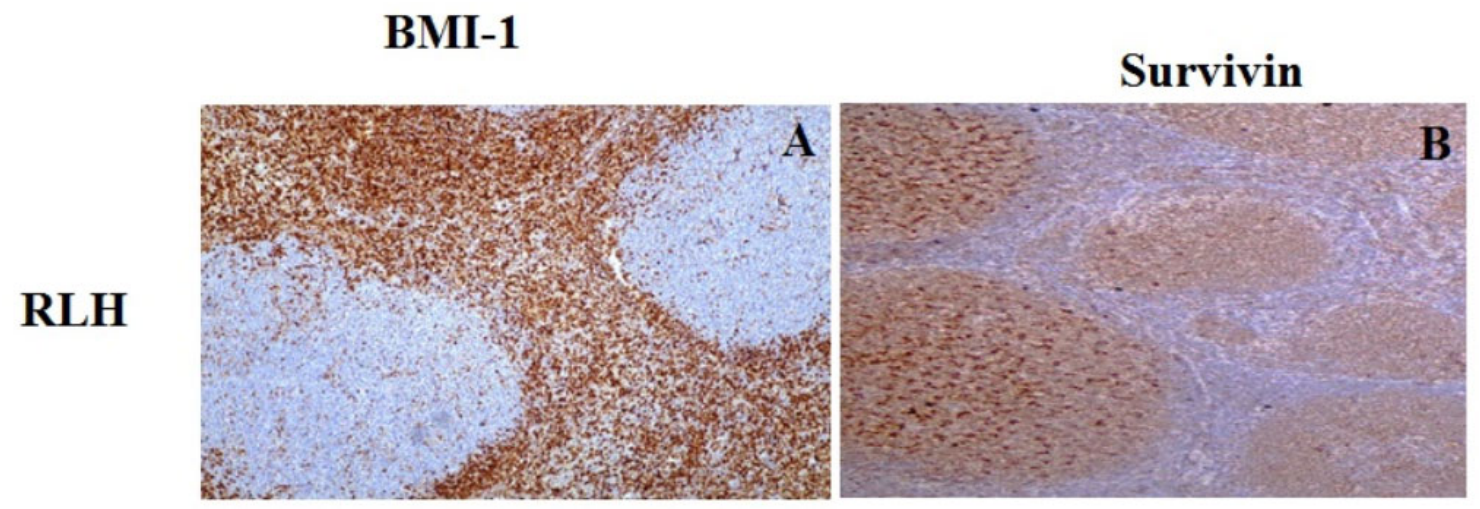

Figure 3. Immunohistochemical staining of BMI-1 and Survivin in RLH A) BMI-1 was detected mainly in the mantle zone (MZ) and interfollicular (IF) area whiles the germinal center (GC) was negative. B) Survivin showed strong staining in the GC and weaker staining in MZ and IF area. 

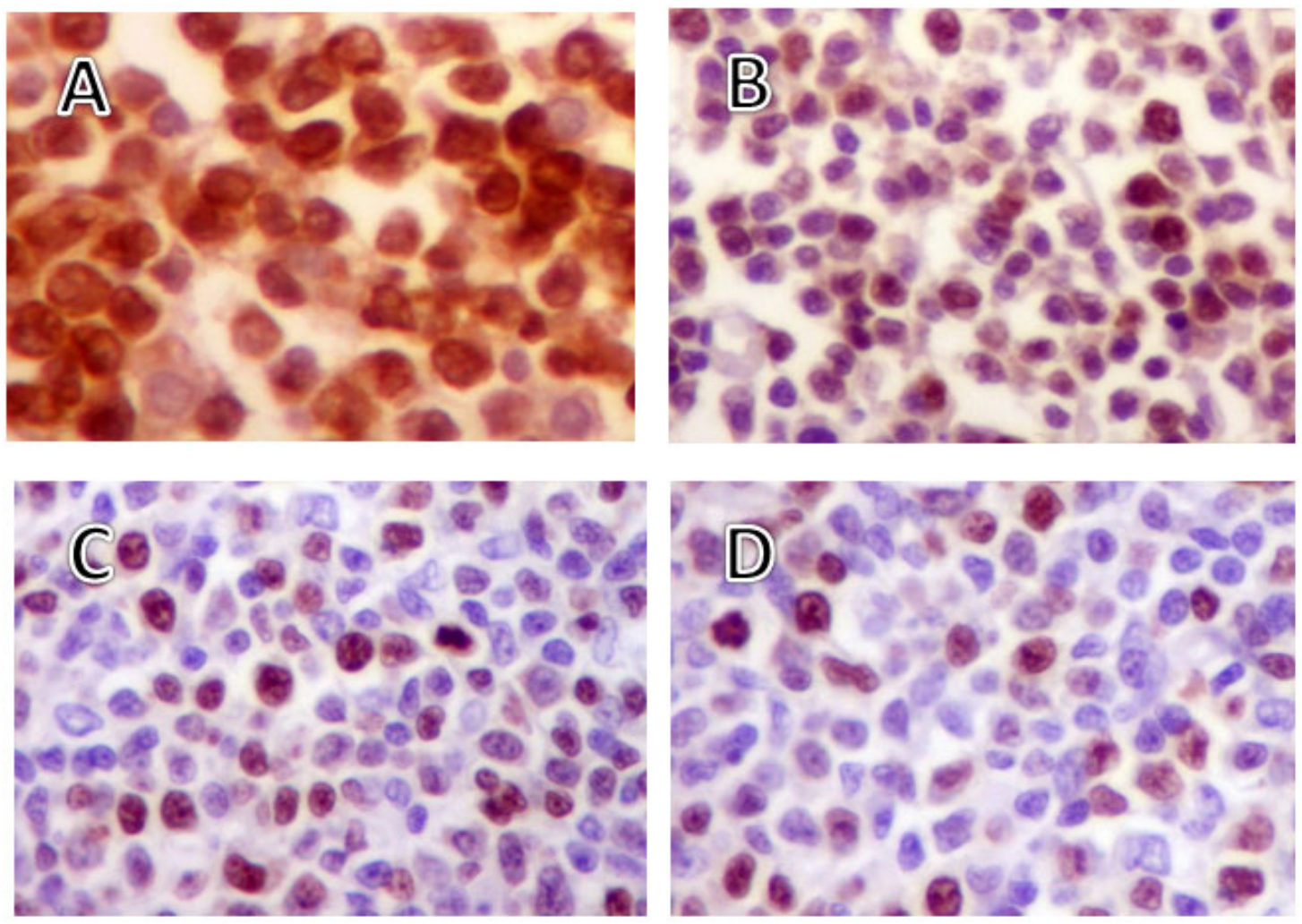

Figure 4. Immunohistochemical staining of BMI-1 and Survivin in B- and T/NK-cell neoplasms. (A and B) Diffuse large B-cell lymphoma germinal center DLBCL-GCB showed high expression of BMI-1 and Survivin respectively. (C and D) Peripheral T cell lymphoma (PTCL) showed high expression of BMI-1 and Survivin respectively.

\subsubsection{High expression of BMI-1 and Survivin in T-cell neoplasms (see Tables 3, and 5)}

In T-cell lymphomas as a whole, the expression of Bmi-1 was diffuse $(75.2 \%)$ with moderate/strong intensity. It ranged from $71.4 \%$ in Anaplastic large cell lymphoma (ALCL), $72.7 \%$ in peripheral $\mathrm{T}$ cell lymphoma PTCL to $80.9 \%$ in T-cell lymphoblastic lymphoma (T-LBL) (see Figure 4C and Table 3). The overall expression of Survivin in TCL was $73.5 \%$ with moderate/strong intensity. It ranged from $63.6 \%$ in PTCL, $76.2 \%$ in ALCL to $78.6 \%$ in T-LBL (see Figure 4D and Table 3). The Kruskal-Wallis Test couldn't reveal a significant change in the expression pattern of BMI-1and survivin in different variants of T-cell lymphomas in this study ( $p=.072, .085$ respectively). (see Table 5)

\subsubsection{Significant differences in the expression of BMI-1 and Survivin between lymphoid neoplasms and nor- mal lymphoid tissues (see Table 4)}

All germinal center lymphomas (BL, DLBCL-GCB, FLG1 and FLG3) revealed significant upregulation in the expression of BMI-1 compared to negative/weak staining in the normal germinal center cells (Mann-Whitney Test $p=.00$ in all). Among post-germinal center cell lymphomas, CLL/SLL and DLBCL-NGCB showed significant increase in BMI-1 staining compared to the corresponding normal cell (MannWhitney Test $p=.02$, and .01 respectively). No statistically significant difference in the expression of BMI-1was found in MCL compared to its expression in the presumed normal counterpart (Mann-Whitney Test $p=.05$ ) (see Table 4). Significant increase in expression of Survivin was found in MCL compared to the corresponding normal cell $(p=.008)$. Among germinal center lymphomas, significant increase in the expression of Survivin compared to corresponding normal cells was found in DLBCL-GCB and FLG3 ( $p=.00$ and .01 respectively). Post germinal center lymphomas, MALT lymphoma, CLL/SLL and PCM showed significant increase in Survivin staining compared to the corresponding normal cells (Mann-Whitney Test $p=.007, .02$, and .03 respectively)(see Table 4). All TCL subtypes in this study showed significant upregulation of both BMI-1 and Survivin when compared to their cell of origin. (Mann-Whitney Test $p=$ .00 for both). PTCL showed upregulation in the expression of both BMI-1 \& Survivin ( $p=.03$ and .009 respectively). ALCL showed significant upregulation of both BMI-1\& Survivin $(p=.009$ and .008 respectively)(see Table 4$)$. 
Table 4. Significant upregulation in the expression of BMI-1 and Survivin in lymphoid neoplasms correlated to its Postulated cell of origin

\begin{tabular}{|c|c|c|c|c|c|c|}
\hline Malignant lymphoma & & $\begin{array}{l}\text { Postulated cell of } \\
\text { origin }\end{array}$ & BMI-1 & & Survivin & \\
\hline MCL & MCL & $\begin{array}{l}\text { Mantle zone of } \\
\text { RLH }\end{array}$ & $p=0.05$ & & $p=.008^{*}$ & \\
\hline Germinal Center B Cell Lymphoma & $\begin{array}{l}\text { BL } \\
\text { DLBCL-GCB } \\
\text { FLG1-2 } \\
\text { FLG3 }\end{array}$ & $\begin{array}{l}\text { GC dark and light } \\
\text { zone }\end{array}$ & $\begin{array}{l}p=.001^{*} \\
p=.00^{*} \\
p=.00^{*} \\
p=.00^{*}\end{array}$ & $p=.00^{*}$ & $\begin{array}{l}p=0.1 \\
p=.00^{*} \\
p=.09 \\
p=.01^{*}\end{array}$ & $p=.001^{*}$ \\
\hline $\begin{array}{l}\text { Non Germinal Center B Cell } \\
\text { Lymphoma }\end{array}$ & $\begin{array}{l}\text { DLBCL non GCB } \\
\text { PCM } \\
\text { PC } \\
\text { CLL/SLL } \\
\text { MALT lymphoma }\end{array}$ & $\begin{array}{l}\text { Post- GC and } \\
\text { plasma cell }\end{array}$ & $\begin{array}{l}p=.01^{*} \\
p=.1 \\
p=.11 \\
p=.02^{*} \\
p=.1\end{array}$ & $p=.02$ & $\begin{array}{l}p=.2 \\
p=.03^{*} \\
p=.05 \\
p=.02^{*} \\
p=.007^{*}\end{array}$ & $p=.001^{*}$ \\
\hline T Cell Lymphoma & $\begin{array}{l}\text { PTCL } \\
\text { ALCL }\end{array}$ & T cell of RLH & $\begin{array}{l}p=.03^{*} \\
p=.009^{*}\end{array}$ & $p=.000^{*}$ & $\begin{array}{l}p=.009^{*} \\
p=.008^{*}\end{array}$ & $p=.000^{*}$ \\
\hline
\end{tabular}

Note. Mann-Whitney Test results MCL: Mantle cell lymphoma, BL: Burkitt lymphoma, DLBCL (GCB): Diffuse large cell B cell lymphoma germinal center type, DLBCL non GCB: Diffuse large B-cell lymphoma non germinal center type, FL G3: Follicular lymphoma grade3, FL G1: Follicular lymphoma grade 1, PCM: Plasma cell myeloma, PC: Plasmacytoma, CLL/SLL: Chronic lymphocytic leukemia/small lymphocytic lymphoma, MALT: Mucosa associated lymphoid tissue, ALCL: Anaplastic large cell lymphoma, PTCL: Peripheral T-cell lymphoma, T-LBL: T-cell lymphoblastic lymphoma, RLH : Reactive lymphoid hyperplasia, GC: Germinal center. Bold figures are statistically significant, $*$ : significant statistical tests ( $p$ value is less than .05).

\subsubsection{Significant positive correlation between BMI-1 and Survivin expressions in $B$ and $T$ cell neoplasms (see Figure 3)}

In B cell lymphoma, BMI expression was considerably positively correlated to Survivin expression (Correlation Coefficient (co): $0.539, p=.00$ ) (see Figure 1A). In T cell lymphoma, there was also significant correlation between them (Correlation Coefficient (co): 0.560, $p=.000$ ) (see Figure 3B).

\subsection{BMI-1 and Survivin expression relation to the prog- nosis of NHL (see Figure 4)}

In the current study, Kaplan-Meier test detected a statistically significant association between OS and expression of both BMI-1 and Survivin. All valid cases with negative BMI1 or survivin were censored. BMI-1 +++ was associated with lowest OS (75\% of the patients were died during the follow-up period of the study). Survivin+++ was associated with lowest OS ( $72 \%$ of the patients were died during the follow-up period of the study). We could not estimate the means and confidence interval for survivin however the test is significant. ( $p=.00$ for BMI-1and survivin) (see Figure $4 \mathrm{~A}, \mathrm{~B})$. However, the test failed to find significant association between EFS and expression of both BMI-1 and Survivin ( $p$ $=.11$, and .1 respectively). (see Figure 4C, D).
Table 5. Expression of Bmi-1 and survivin among different subtypes of B and $\mathrm{T}$ cell neoplasms and normal lymphoid tissue

\begin{tabular}{lll}
\hline $\begin{array}{l}\text { Malignant lymphoma } \\
\text { normal control }\end{array}$ & BMI-1 & Survivin \\
\hline B-cell neoplasms & & \\
BL & & \\
DLBCL- GCB & & \\
DLBCL non GCB & $p=.02^{*}$ & $p=.04^{*}$ \\
FLG3 & & \\
MCL & & \\
FLG1 & & \\
PCM & & \\
PC & & \\
CLL/SLL & & \\
MALT & & \\
T/NK-cell neoplasms & $p=.072$ & \\
T-LBL & & \\
PTCL & & \\
ALCL & & \\
RLH B cells & & \\
Mantle zone & & \\
GC light \& dark zone B cells & $p=.003^{*}$ & \\
Post GC B-cells, plasma cells & & \\
\hline
\end{tabular}

Note. Kruskal-Wallis Test results MCL: Mantle cell lymphoma, BL: Burkitt lymphoma, DLBCL (GCB): Diffuse large cell B cell lymphoma germinal center type, DLBCL non GCB: Diffuse large B- cell lymphoma non germinal center type, FL G3: Follicular lymphoma grade3, FL G1: Follicular lymphoma grade 1, PCM: Plasma cell myeloma, PC: Plasmacytoma, CLL/SLL: Chronic lymphocytic leukemia/small lymphocytic lymphoma, MALT: Mucosa associated lymphoid tissue, ALCL: Anaplastic large cell lymphoma, PTCL: Peripheral T-cell lymphoma, T-LBL: T-cell lymphoblastic lymphoma, RLH : Reactive lymphoid hyperplasia, GC: Germinal center. Bold figures are statistically significant. *: significant statistical tests ( $p$ value is less than .05 ).

ISSN 1925-4067 E-ISSN 1925-4075 


\section{Discussion}

NHLs have different patterns of behavior and responses to treatment. ${ }^{[28]}$ Recently gene analysis allows us to better recognize the biology and molecular classification of such tumors. Genetic studies discovered new oncogenic pathways involved in lymphomagenesis in atrial to explain these heterogeneities and ultimately lead to modified diagnostic and therapeutic plan for patients. ${ }^{[1]}$ BMI1 expression abnormalities have led to evolution and progression of several types of hematologic malignancies through increasing the proliferative activity of the malignant cells. ${ }^{[9]}$ Enhanced survivin expression is implicated in aggressive NHL rather than indolent type through inhibition of apoptosis. ${ }^{[29]}$ As regard the clinical clinicopathological characteristics of the studied cases, in the present study, most of the BCL were male, mean age $58 \pm 13$ years, presented in stage 3 with low incidence of extra-nodal. These demographic data are partially in agreement to the international and national studies, ${ }^{[30,31]}$ however our study revealed higher frequency of DLBCL either GC or NGC $(122 / 267,46 \%)$ which is relatively higher than reported in the literature that represent one third of NHL, be explained by the delay in diagnosis of patients in rural areas like Dakahleia as the patient seeks medical treatment very late. This gave time to low grade indolent lymphoma to transform into high grade lymphoma (DLBCL). In our study, the expression pattern of BMI-1 \& survivin was significantly related to stage and overall survival of NHL patients. These results are inconvenient Bhattacharyya et al. 2012 study and $\mathrm{He}$ et al. 2015. ${ }^{[32,33]}$ These results are attributed to their role in oncogenesis and progression of NHL. Previous studies reported that Survivin expression in RLH is ranging between 13\%-38\%. BMI-1 was found more in resting cells of RLH. ${ }^{[18,29]}$ In consistence with these data, the present study found both BMI-1 and Survivin were expressed in post germinal center cells (post germinal center B-cells, and plasma cells) and $\mathrm{T}$ cells (interfollicular $\mathrm{CD} 3+\mathrm{T}$, and follicular CD4+ T-helper cells). In the mantle zone, BMI-1 expression was significantly stronger than that of Survivin while in the dividing cells of the germinal center, the situation was reversed. Survivin expression was evidently higher than BMI-1 in both dark and light zones of the germinal center. Mazur et al. 2004 reported that, survivin is highly expressed in rapidly dividing fetal and embryonic cells, but undetectable in terminally differentiated adult cells. ${ }^{[29]}$ This is relatively consistent with its expression in the dividing cells of germinal center cells. However the fact that germinal center cells switch on pro-apoptotic proteins but still retain a high expression of Survivin is interesting. This observation requires further studies. Avramović et al. 2015 observed that greater apoptotic activity can be accompanied by stronger

Published by Sciedu Press expression of survivin in the reactive follicles of tonsils with recurrent tonsillitis. They supposed that survivin is expressed in the cells which have already received some death signal and which attempt to prevent dying by stopping the cell cycle. This can partially explain the difference in expression pattern of BMI-1 and Survivin in RLH. This means that expression pattern of survivin is independent of proliferative activity. ${ }^{[34]}$ Upregulation of BMI-1 was found in all germinal center lymphomas: BL, DLBCL, FLG1 and FLG3 $(p=.00)$ in comparison to the cell of origin. However MCL and some post germinal center lymphoma (PCM, PC.MALT) did not show significant upregulation of BMI-1 compared to their corresponding cell of origin. CLL/SLL, and DBCL-NGC showed significant difference in expression compared to the cell of origin. Also upregulation of BMI-1 was found in $\mathrm{T}$ cell lymphomas in comparison to the cell of origin. The increase in the expression of BMI- 1 is settled by the development of lymphoma in transgenic mice, in addition BMI1 cooperates with c-Myc in generation of lymphomas, by inhibiting its apoptotic function and down regulation of p16 INK4a and p19ARF. It is also consistent with Raaphorst et al. 2005 that reports enhanced expression of BMI-1 lead to increase the activity of telomerase and immortalization. ${ }^{[15]} \mathrm{We}$ found significant variability in the expression of BMI-1 in different variants of B cell lymphomas. It was evident that its expression was relatively higher in naïve pregerminal center lymphoma (MCL) and most of post germinal center cell lymphoma (MALT , PC, CLL/SLL) than most of germinal center lymphoma (BL, FLG1-3). These results are agreed with that was reported by Sahasrabuddhe 2016 study. ${ }^{[9]}$ However the current study confirmed that DLBCL GC strongly expressed BMI-1 than NGC type. This was against that reported by Sahasrabuddhe 2016, this might be due to variability of the number of cases of each study (see Table 3 ) or that we depend upon IHC in the differentiation between DLBCL-GC and NGC rather than cDNA microarray analysis. This was also noted in Abd Al Kader et al. 2013 study and reinforced by Bmi-1 expression was not limited to the ABC type of DLBCL. ${ }^{[10,14]}$ There was no significant difference in expression of BMI-1 in different variants of TCL in our study as the 3 subtypes that was present were TLBL, PTCL, and ALCL and the expression of BMI-1 was high in all of them. Abd Al Kader et al. 2013 study showed difference of expression of BMI-1 in different variants of TCL because their study included more subtypes of TCL. ${ }^{[10]}$ The current study showed that Survivin is upregulated in all NHL either B or TCL. The difference in expression between the neoplastic tissue and normal counterpart was statistically significant difference in MCL, germinal center lymphomas, post germinal center lymphoma and T/NK- cell lymphomas. This is 
consistent with reports that Survivin inhibit apoptosis and stimulate proliferation through interaction with Cdk4. ${ }^{[18-20]}$ We found significant difference in survivin expression among subtypes of BCL but not TCLL. These are in convenient with the results of Mazur et al. 2004 study. Both of us found significant survivin upregulation in aggressive rather than indolent lymphoma variants. ${ }^{[29]}$ Previous studies on BMI-1 role in the epigenetic regulation of Survivin are rather inconsistent. Acquati et al. 2012 suggested that BMI-1 leads to suppression of Survivin expression. ${ }^{[35]}$ On the other hand, Bhattacharyya et al. 2011 suggested that enhanced expression of BMI-1 leads to stabilization of expression of survivin and both have a big role in the chemoresistance in DLBCL by apoptosis inhibition. ${ }^{[33]}$ We found that BMI-1 and Survivin expression showed significant positive correlation in $\mathrm{B}$ and $\mathrm{T}$ cell lymphomas. We also found that despite differences in expression of both BMI-1 and Survivin in RLH as well as neoplastic lymphoid tissues showed a lot of harmony between the two proteins. The exact role that BMI-1 plays in the regulation of Survivin among other regulatory mechanisms requires further research. In our study, significant difference between OS and expression of both BMI-1 and Survivin are detected. The negative BMI-1 was related to the highest survival rate while, BMI-1 +++ was associated with lowest survival rate. These results are confirming its role in disease progression or prognosis by enhancing the proliferation and preventing apoptosis by several mechanisms. These conclusion is reached by Bhattacharyya et al. 2012 study. ${ }^{[33]}$ Also higher expression of survivin are associated with poor overall survival comared to negative or low expression of it. this result is in agreement of the meta analysis done about the prognostic role of survivin in NHL in He et al.2015 study. ${ }^{[32]}$ Accordingly higher expression of BMI-1 and survivin will augment drug resistance and motivates the search for targeted therapy against them as a new therapeutic modality in NHL. In conclusion, we report significant enhancement of BMI-1 and Survivin in both B and T cell lymphomas compared to reactive lymphoid tissue. We report significant positive correlation between the two proteins. We also report significant relation of them to the overall survival. We suggest further research to better understand the relation between the two proteins and the possible use them in anew targeted therapy of lymphoma.

\section{AUTHORS' CONTRIBUTION}

Authors contributed equally in this work.

\section{ACKNOWLEDGEMENTS}

The authors gratefully acknowledge all staff members of the Pathology department of Oncology Center, Faculty of Medicine, Mansoura University, Egypt.

\section{CONFLicts of InTEREST Disclosure}

No potential conflicts of interest are disclosed.

\section{REFERENCES}

[1] Hendrik N, Bernd D, Georg L. Pathogenesis of non-Hodgkin's lymphoma. J Clin Oncol. 2011; 29: 1803-1811. PMid:21483013. https://doi.org/10.1200/JC0.2010.33.3252

[2] Van FJ, Raaphorst FM, Blokzij1 T, et al. Cycling cells and degree of malignancy in B-cell non-Hodgkin lymphoma Coexpression of BMI1 and EZH2 polycomb-group proteins is associated with cycling cells and degree of malignancy in B-cell non-Hodgkin lymphoma. Blood. 2010.

[3] Hopp L, Nersisyan L, Löffler-wirth H, et al. Epigenetic Heterogeneity of B-Cell Lymphoma: Chromatin Modifiers. Genes. 2015 1076-1112. PMid:26506391. https://doi .org/10.3390/gene s6041076

[4] Federico M, Vitolo U, Zinzani PL, et al. Prognosis of follicular lymphoma: a predictive model based on a retrospective analysis of 987 cases. 2011.

[5] Strahl BD, Allis CD. The language of covalent histone modifications. Nature. 2000; 403: 41-45. PMid:10638745. https ://doi .org/10 $.1038 / 47412$

[6] Vanasse GJ, Concannon P, Willerford DM. Regulated genomic instability and neoplasia in the lymphoid lineage. Blood. 1999; 94 3997-4010.

[7] Warnke RA, Weiss LM, Chan JKC. Malignant lymphomas: an overview. Tumors Lymph Nodes Spleen. 2000; 53-58.
[8] Pirrotta V. Polycomb Silencing and the Maintenance of Stable Chromatin States, in: Springer, Berlin, Heidelberg, 2013: pp. 205-228. https://doi .org/10.1007/978-3-540-69111-2_10

[9] Sahasrabuddhe AA. BMI1: A Biomarker of Hematologic Malignancies, Biomark. Cancer. 2016; 8: BIC.S33376. PMid:27168727. https://doi.org/10.4137/BIC.S33376

[10] Abd KL, Oka T, Takata K, et al. In aggressive variants of nonHodgkin lymphomas, Ezh2 is strongly expressed and polycomb repressive complex PRC1.4 dominates over PRC1.2. Virchows Arch. 2013; 463: 697-711. PMid:23948956. https://doi .org/10.100 7/s00428-013-1428-y

[11] Rosenwald A, Brown PO, Weisenburger DD, et al. Distinct types of diffuse large B-cell lymphoma identified by gene expression profiling, Nature. 2002; 403: 503-511. PMid:10676951. https: //doi.org/10.1038/35000501

[12] AlJohani N, Choi SJ, Day AG, et al. Abundant expression of BMI1 in follicular lymphoma is associated with reduced overall survival, Leuk. Lymphoma. 2018; 59: 2211-2219. PMid:29251058. https://doi.org/10.1080/10428194.2017.1410883

[13] Wang L, Brown JL, Cao R, et al. Hierarchical recruitment of polycomb group silencing complexes. Mol Cell. 2004; 14: 637-646. PMid:15175158. https://doi.org/10.1016/j.molcel. 2004. 05.009 
[14] Vos JW, Ossenkoppele JC, van Galen PE, et al. Raaphorst, Expression of the polycomb-group gene BMI1 is related to an unfavourable prognosis in primary nodal DLBCL. J Clin Pathol. 2006; 60: 167172. PMid:16837630. https://doi.org/10.1136/jcp. 2006.0 38752

[15] Raaphorst FM. Deregulated expression of Polycomb-group oncogenes in human malignant lymphomas and epithelial tumors. Hum Mol Genet. 2005; 14: 93-100. PMid:15809278. https://doi .or $\mathrm{g} / 10.1093 / \mathrm{hmg} / \mathrm{ddi} 111$

[16] Wang CG, Ye YJ, Yuan J, et al. EZH2 and STAT6 expression profiles are correlated with colorectal cancer stage and prognosis. World J. Gastroenterol. 2010; 16: 2421-2427. PMid:20480530. https://doi.org/10.3748/wjg.v16.i19.2421

[17] Morin RD, Johnson NA, Severson TM, et al. Somatic mutations altering EZH2 (Tyr641) in follicular and diffuse large B-cell lymphomas of germinal-center origin. Nat Genet. 2010; 42: 181-185. PMid:20081860. https://doi .org/10.1038/ng.518

[18] Bedewy ML, Elgammal MA, Bedewy ML, et al. Assessing DcR3 expression in relation to survivin and other prognostic factors in $\mathrm{B}$ cell non-Hodgkin's lymphoma. Annals of Hematology. 2013; 92: 1359-1367. PMid:23652586. https://doi.org/10.1007/s002 77-013-1775-4

[19] Li J, Wu H. Expression of survivin in Human Non-Hodgkin Lymphoma and Its Correlation with Proliferation and Angiogenesis. Journal of Huazhong University of Science and Technology. 2006; 26: 504-507. https://doi.org/10.1007/s11596-006-0504-9

[20] Ambrosini G, Adida C, Altieri DC. A novel anti-apoptosis gene, survivin, expressed in cancer and lymphoma. Nat Med. 1997; 3: $917-$ 921. PMid:9256286. https://doi .org/10.1038/nm0897-917

[21] Zhang Y, Zhou S, Yan H, et al. MiR-203 inhibits proliferation and self-renewal of leukemia stem cells by targeting survivin and Bmi-1. Sci Rep. 2016; 6: 19995. PMid:26847520. https://doi.org/10 .1038/srep19995

[22] Bentley S. WHO Classification of Tumours: Pathology and Genetics. Tumours of Haematopoietic and Lymphoid Tissues. 2003. https://doi.org/10.1046/j.1365-2257.2003.00518.x

[23] Hans CP, Weisenburger DD, Greiner TC, et al. Confirmation of the molecular classification of diffuse large B-cell lymphoma by immunohistochemistry using a tissue microarray. Blood. 2004; 103 : 275-82. PMid:14504078. https://doi .org/10.1182/blood-2 003-05-1545
[24] Foda RM. No-cost manual method for preparation of tissue microarrays having high quality comparable to semiautomated methods. Appl Immunohistochem Mol Morphol. 2013; 21: 271-4.

[25] Shebl AM, Zalata KR, Amin MM, et al. An inexpensive method of small paraffin tissue microarrays using mechanical pencil tips. Diagn Pathol. 2011; 6: 117. PMid:22132713. https://doi .org/10.118 6/1746-1596-6-117

[26] Soliman NA, Yussif SM. Ki-67 as a prognostic marker according to breast cancer molecular subtype. Cancer Biol Med. 2016; 13: 496504. PMid:28154782. https://doi.org/10.20892/j.issn. 20 95-3941.2016.0066

[27] Yussif SM, Soliman N. Assessment of neuroendocrine markers in different molecular subtypes of invasive breast carcinoma and its impact on prognosis. Merit Reasearch Journals. 2018; 6(5):204-214.

[28] Hadzi-Pecova L, Petrusevska G, Stojanovic A. Non-Hodgkin's lymphomas: immunologic prognostic studies. Prilozi. 2007; 28: 39-55.

[29] Mazur G, Wróbel T, Urbaniak J, et al. Survivin expression in lymph nodes affected by lymphoma and reactive hyperplasia. Rocz Akad Med Bialymst. 2004; 49: 76-8.

[30] Kondo E, Yoshino T. Expression of apoptosis regulators in germinal centers and germinal center-derived B-cell lymphomas: Insight into B-cell lymphomagenesis. Pathology International. 2007; 391-397. PMid:17587238. https://doi .org/10.1111/j.1440-1827.20 $07.02115 . x$

[31] El Bolkainy, Nouh MA. Pathology of Cancer. 4th ed. Cairo Press, Cairo, Egypt, 2013.

[32] He C, Liu Z, Ji J, et al. Prognostic value of survivin in patients with non-hodgkin's lymphoma: A meta-analysis. Int J Clin Exp Med. 2015; 8(4):5847-54.

[33] Bhattacharyya J, Mihara K, Ohtsubo M, et al. Kimura, Overexpression of BMI-1 correlates with drug resistance in B-cell lymphoma cells through the stabilization of survivin expression. Cancer Sci. 2012; 103: 34-41. PMid:21999765. https://doi.org/10.1111/ j.1349-7006.2011.02121.x

[34] Avramović V, Petrović V, Jović M, et al. Quantification of cells expressing markers of proliferation and apoptosis in chronic tonsilitis. Acta Otorhinolaryngol Ital. 2015; 35(4):277-84.

[35] Acquati S, Greco A, Licastro D, et al. Epigenetic regulation of survivin by Bmil is cell type specific during corticogenesis and in gliomas. Stem Cells. 2013; 31: 190-202. PMid:23132836. https : //doi.org/10.1002/stem.1274 